Copyright (C) 2014 by Academic Publishing House Researcher

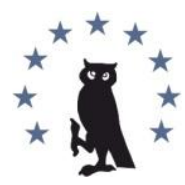

Published in the Russian Federation

European Researcher

Has been issued since 2010.

ISSN 2219-8229

E-ISSN 2224-0136

Vol. 84, No. 10-1, pp. 1728-1735, 2014

DOI: $10.13187 /$ er.2014.84.1728

www.erjournal.ru

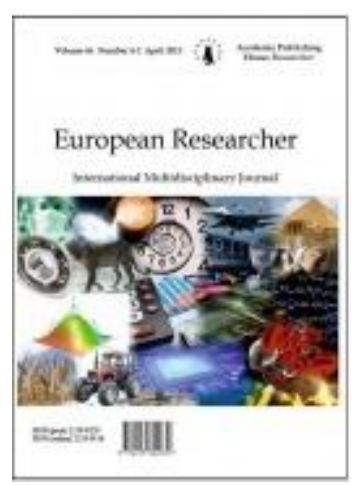

Biological sciences

Биологические науки

UDC 58.009

\title{
A Study of the Major Phytocoenotic and Economic Attributes of Fragaria Viridis (Duch.) Weston in Natural Conditions (through the Example of East Kazakhstan Region)
}

\author{
${ }^{1}$ Tatiana A. Vdovina \\ ${ }^{2}$ Olga A. Serova \\ 3 Nina M. Kadantseva
}

1-3 Altay botanical Garden CS MES RK, Kazakhstan

071300, Ridder city, Ermakov st. 1

${ }^{1} \mathrm{PhD}$ (Biology), Leading Researcher

E-mail: altai_bs@mail.ru

${ }^{2}$ Senior agronomist

E-mail: altai_bs@mail.ru

3 Junior Researcher

E-mail: Nina_badreyeva@mail.ru

\section{Abstract}

This article provides data on the phytocoenotic and economic-morphological attributes of Fragaria viridis Duch., green strawberry, in various locations. The most sustainable habitat for the existence of this species has been located near the village of Zimoviye. The ratio between the generative and vegetative species in the examined coenopopulations allows us to subsume them under the invasional and normal types.

Keywords: Fragaria viridis Duch.; location; coenopopulation; variability; attribute

\section{Введение}

Рациональное использование дикорастущих плодовых и ягодных растений, произрастающих в природных условиях Восточно-Казахстанской области, является одним из звеньев Продовольственной безопасности Республики Казахстан. В настоящее время в Восточно-Казахстанской области произрастает более 50 видов плодовых и ягодных растений, генетический потенциал которых способствует сохранению биоразнообразия и проведению селекционных работ.

F. viridis Duch. - земляника зеленая является ценным пищевым и лекарственным растением. Плоды содержат: глюкозы - 4,98\%, сахарозы - 6,33\%, свободных кислот 0,55\% (в том числе фолиевой кислоты - (В9) - 0,24\%, аскорбиновой кислоты - 50-70 \%), Р-активных веществ - 0,25-0,75 \%, азотсодержащих веществ - 1,49 \%, золы - 1,22\%, воды - 
82,3 \%. Кроме того, плоды содержат каротин, а также дубильные, флавоновые и пектиновые вещества, антоциановые соединения, эфирное масло, фитонциды, микроэлементы. В листьях найдены дубильные вещества, от 300 до 438 ма аскорбиновой кислоты, эфирное масло [1]. Земляника обладает самым разнообразным действием: противовоспалительным, рано заживляющим, потогонным, мочегонным, кровоостанавливающим и вяжущим. Регулирует обмен веществ, оказывает противосклеротическое действие, улучшает состав крови. Плоды ценятся как средство, растворяющее камни печени и почек и не допускающее их возникновение, а также как средство при подагре [2; 3].

F. viridis Duch. - земляника зеленая многолетнее корневищное травянистое растение, до 25 см высотой, с многочисленными придаточными корнями. Стебель прямостоящий одинаковой длины с листьями или немного длиннее их, густо одетый оттопыренными, а в верхней части нередко прилегающими волосками; прилистники узкие, коричневые; корневые листья на черешках, мохнатых от густо одевающих их оттопыренных волосков, средний листочек на коротком черешочке, яйцевидный или обратнояйцевидный, стеблевые сидячие или на очень коротком черешочке, косояйцевидные, с мелкими туповатыми зубцами с каждой стороны, конечный зубец маленький, значительно короче соседних, сверху листья зеленые, блестящие, прижато-волосистые, снизу сероватые от густо прилегающих, шелковисто-блестящих волосков, особенно густых на выдающихся жилках; соцветие небольшое, щитковидное, рыхлое, малоцветковое, одетое при основании цельным или трехраздельным верхушечным листом; цветоножки коротковатые, одетые прижатыми или изредка горизонтально-оттопыренными волосками (у нижних цветков в соцветии); цветки сравнительно крупные, до 2,5 cм в диаметре, обычно обоеполые; чашелистики треугольные, ланцетные, иногда длиннее венчика, прижато-волосистые, при плодах прижатые к ним, наружные чашелистики одинаковой длины с чашелистиками или несколько длиннее их, линейно-ланцетные, на верхушке иногда расщепленные; лепестки округлые или обратнояйцевидные, заходящие друг за друга краями, коротконоготковые, желтовато-белые; тычинки вдвое длиннее головок пестиков (у неплодоносящих цветков) или одинаковой с ними длины (у плодущих); цветоложе волосистое; плоды шаровидные или обратнояйцевидные, при основании суженные, большей частью желтовато-белые, лишь на верхушке красноватые, реже целиком розовые или бледно-красные, со слегка погруженными в мякоть плода семянками, трудно отделяющиеся от цветоложа, душистые [4].

Распространение в Казахстане: 2. Тоб-Ишим. 3. Ирт., 4. Семип. бор., 5. Кокчет., 12. Зайс., 22. Алтай, 23. Тарб., 24. Джунг. Алат., 25. Заил. Кунг. Алат., 27. Кирг. Алат., 28. Карат., 29. Зап. ТШ.

Общее распространение: Европ. част СССР, Кавказ, Зап. и Вост. Сибирь, почти вся Зап. Европа, Южн. Средиземноморье (Флора Казахстана, т.4.) [5].

Земляника зеленая (клубника) - вид экологически пластичный. Растет на осиновоберезовых колках, на открытых травянистых горных склонах, опушках и полянах горных лесов, лугах и луговых степях.

Целью работы явилось изучение пространственной структуры ценопопуляций Fragaria viridis в различных растительных ассоциациях, которая отражает ее возрастное состояние, продуктивность, динамику во времени, в конкретных условиях ценотической конкуренции. Изучение этого вопроса позволит понять механизм адаптации и устойчивости этого вида в различных фитоценозах, установить действие антропогенного фактора и выявить факторы, определяющие оптимальное и стабильное плодоношение.

\section{Материалы и методы}

Ценопопуляцию принимали, как совокупность всех особей вида в конкретном фитоценозе и популяцию в более широком объеме, ограниченную конкретным географическим регионом. Описание растительности проводили по общепринятым для геоботанических исследований методикам [6]. Распространение клубники описывали как диффузное, кустиками - друг от друга на небольшом расстоянии, либо сплошными куртинами по методике А.А. Скрябиной [7]. Для составления характеристики ценопопуляции: определяли урожайность, плотность (количество растений на $1 \mathrm{~m}^{2}$ ), массу средней ягоды, массу 100 ягод, а также морфологические признаки: такие как высота 
цветоноса, толщина цветоноса, количество цветков на цветоносе, длина чашелистиков, ширина чашелистиков и т.д. В каждом местонахождении методом трансект закладывали пробные площадки размером $1 \mathrm{M}^{2}$, в количестве 9-12 шт.

За счетную единицу приняты генеративные растения, которые вступили в фазу плодоношения и молодые ювенильные растения. По их соотношению ценопопуляцию (ЦП) классифицировали, как ЦП инвазионного, нормального и регрессивного типа.

Изучение изменчивости проводили по методике А.И. Ирошникова, С.А. Мамаева, Л.Ф. Правдина, М.А. Щербакова [8]. Изменчивость оценивали по величине коэффициента вариации: меньше $12 \%$ - уровень изменчивости низкий, 13-20 \% - средний, 21-40 \% высокий, более 40 \% - очень высокий.

\section{Обсуждение}

В связи с изучением и сохранением биоразнообразия растений назрела необходимость изучения ЦП Fragaria viridis (клубники) в местах: близ с.с. Черемшанка, Бутаково, Ливино, Зимовье, Орловка, Быструха, в окрестностях г. Риддер на г. Козлушка, ур. Чащино, на сопках в районах Большой и Малой Таловки, Шаравки, Крольчатника, около Сибинских озер, с. Самарка, в окрестностях г. Серебрянск, с.с. Печи, Черемошка, где проводятся массовые заготовки ягод местным населением. Только в с. Орловка ежегодно собирают от 4 до 7 тонн ягод.

Наиболее полное изучение Fragaria viridis проводилось близ с. Зимовье, на открытой поляне вдоль р. Ульбинка, юго-восточном склоне г. Сокольная, ур. Чашино, в северовосточной части Быструшинского водохранилища и насыпи, которая сделана при возведении дамбы. Изучение флористического состава по пробным площадям помогает полнее представить условия, в которых проводилось исследование. В большинстве местообитаний кустарниковый ярус представлен следующими видами: Cotoneaster melanocarpus Fisch. ex Blytt, Lonicera tatarica L., Rosa acicularis Lindl., $R$. laxa Retz. Наибольшее распространение в травянистом покрове получили: Poa angustifolia L., P. pratensis L., Festuca valesiaca Gaudin, Thalictrum flavum L., Achillea millefolium L., Pedicularis proboscidea Stev., Echium vulgare L., Viola hirta L., Artemisia campestris L., Potentilla virgata Lehm., P. chrysantha Trev., Galium verum L., Crepis sibirica L., Phlomoides tuberosa (L.) Moench, Poligala sibirica L., Gentiana decumbens L., Vicia cracca L. Veronica sp., Scabiosa ochroleuca L., Origanum vulgare L., Bupleurum longifolium subsp. aureum (Fisch.ex Hoffm.) Soo, Medicago falcata L., Myosotis krylovii Serg., Oxytropis teres (Lam.) DC., Sanguisorba officinalis L., Glechoma hederacea L., Dracocephalum nutans L., Alyssium obovatum (C.A. Mey.) Turcz., Nonea pulla (L.) DC., Geranium pratense L., Lavatera thuringiaca L., Geum rivale L, Thlaspi arvense L., Visia megalotropis Ledeb., Trifolium pratense L., Tanacetum vulgare L., Agrimonia pilosa Ledeb., Euphorbia macrorhiza C.A. Mey. По доминированию тех или иных видов растений определены типы сообществ.

Ценопопуляция клубники на открытой поляне близ с. Зимовье занимает площадь 106 га. Общее проективное покрытие земляники составляет $15 \%$. Распространение клубники диффузное, кустиками - друг от друга на расстоянии 20-45 cм, либо сплошными куртинами от 6 до $13 \mathrm{M}^{2}$. Такое размещение является одним из элементов устойчивости. При подсчете генеративных растений, которые вступили в фазу плодоношения и молодых ювенильных растений нами было отмечено, что в этой популяции наиболее высокая плотность, на 1 кв. м. насчитывается от 100 до 247 растений (таблица 1).

\section{Фитоценотическая характеристика ценопопуляций Fragaria viridis (Duch.) Weston}

Таблица 1

\begin{tabular}{|c|c|c|c|c|c|}
\hline Местонахождение & $\begin{array}{c}\text { Тип } \\
\text { сообщества }\end{array}$ & $\begin{array}{c}\text { Плотность } \\
\text { (кол-во } \\
\text { растений } \\
\left.\text { на } 1 \mathrm{M}^{2}\right)\end{array}$ & 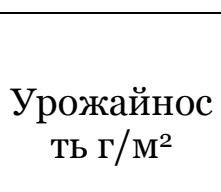 & $\begin{array}{c}\text { Масса } \\
\text { средней } \\
\text { ягоды, г }\end{array}$ & $\begin{array}{c}\text { Масса } \\
\text { крупной } \\
\text { ягоды, г }\end{array}$ \\
\hline Близ с. Зимовье & Разнотравный & $100-247$ & $70-123$ & 0,53 & 2,0 \\
\hline
\end{tabular}




\begin{tabular}{|c|c|c|c|c|c|}
\hline $\begin{array}{l}\text { Открытая } \text { поляна } \\
\text { вдоль р. Ульбинка }\end{array}$ & $\begin{array}{l}\text { Осоково } \quad- \\
\text { разнотравный }\end{array}$ & $60-100$ & $23-30$ & 0,48 & 1,0 \\
\hline $\begin{array}{l}\text { Юго-восточная } \\
\text { часть г. Сокольная } \\
\text { (Алтайский } \\
\text { ботанический сад) }\end{array}$ & $\begin{array}{l}\text { Злаково- } \\
\text { разнотравный }\end{array}$ & $86-144$ & $18-36$ & 0,50 & 0,9 \\
\hline Урочище Чашино & Разнотравный & $120-168$ & $30-58$ & 0,51 & 1,3 \\
\hline $\begin{array}{l}\text { Северо-восточная } \\
\text { часть Быстр. } \\
\text { водохранилища и } \\
\text { насыпь дамбы }\end{array}$ & $\begin{array}{l}\text { Злаково- } \\
\text { разнотравный } \\
\text { (преимуществ } \\
\text { енно степные } \\
\text { виды) }\end{array}$ & $85-120$ & $26-40$ & 0,41 & 0,8 \\
\hline
\end{tabular}

Причем, на многих пробных площадках превалируют вегетативные растения, такое соотношение позволяет отнести ЦП к инвазионному типу (с доминированием молодых особей). Примерно одинаковое соотношение данных особей на пробных площадках позволяет охарактеризовать их как ЦП нормального типа.

Изучение морфологических признаков показало, что высота цветоносов изменяется от 10,9 до 20,8 cм., количество цветков и ягод на одном цветоносе 4-7 шт., а количество цветоносов на растении 1-2 шт. Растения мощные, толщина цветоноса находится в пределах 1,2-2,1 мм (таблица 2).

Таблица 2

Характеристика морфологических и хозяйственных признаков земляники зеленой Fragaria viridis (Duch.) Weston. в различных метонахождениях

\begin{tabular}{|c|c|c|c|c|}
\hline \multirow[b]{2}{*}{ Показатель } & \multicolumn{4}{|c|}{ Местонахождение } \\
\hline & $\begin{array}{l}\text { Окрестности } \\
\text { с. Зимовье }\end{array}$ & $\begin{array}{c}\text { Юго-восточ. } \\
\text { склон г. } \\
\text { Сокольная }\end{array}$ & $\begin{array}{c}\text { Возле } \\
\text { Чашинского } \\
\text { водохранил. }\end{array}$ & $\begin{array}{c}\text { Сев-вост часть } \\
\text { Быструш. } \\
\text { водохранил. }\end{array}$ \\
\hline $\begin{array}{l}\text { Масса } 100 \text { плодов, г (ср. } \\
\text { знач.) } \\
\text { Лимиты }\end{array}$ & $\begin{array}{c}53,1 \\
40,3-66,7\end{array}$ & $\begin{array}{c}49,57 \\
38,7-60,7\end{array}$ & $\begin{array}{c}49,0 \\
32,7-62,2\end{array}$ & $\begin{array}{c}40,1 \\
28,9-51,3\end{array}$ \\
\hline $\begin{array}{l}\text { Высота цветоноса, см } \\
(\mathrm{M} \pm \mathrm{m}) \\
\mathrm{C}, \% \\
\mathrm{P}, \% \\
\text { Лимиты }\end{array}$ & $\begin{array}{c}15,5 \pm 1,6 \\
15,8 \\
3,7 \\
10,9-20,8\end{array}$ & $\begin{array}{c}11,7 \pm 1,3 \\
19,1 \\
4,2 \\
9,9-17,2\end{array}$ & $\begin{array}{c}8,8 \pm 0,8 \\
12,8 \\
3,2 \\
7,6-9,9\end{array}$ & $\begin{array}{c}10,1 \pm 1,6 \\
23,9 \\
5,9 \\
9,5^{-10,7}\end{array}$ \\
\hline $\begin{array}{l}\text { Толщина цветоноса, мм } \\
\text { Лимиты }\end{array}$ & $1,2-2,1$ & $1,1-2,0$ & $1,0-1,7$ & $1,3-1,8$ \\
\hline $\begin{array}{l}\text { Количество цветков } \\
\text { цветоносе, шт. }(\mathrm{M} \pm \mathrm{m}) \\
\mathrm{C}, \% \\
\mathrm{P}, \% \\
\text { Лимиты }\end{array}$ & $\begin{array}{c}6,1 \pm 0,7 \\
21,6 \\
5,0 \\
5,5-6,6\end{array}$ & $\begin{array}{c}5,5 \pm 0,9 \\
24,5 \\
5,2 \\
4,4-6,5\end{array}$ & $\begin{array}{c}6,2 \pm 0,7 \\
20,1 \\
4,6 \\
5,6-7,0\end{array}$ & $\begin{array}{c}6,9 \pm 0,6 \\
18,5 \\
4,3 \\
6,8-7,1\end{array}$ \\
\hline $\begin{array}{l}\text { Длина чашелистиков, мм } \\
(\mathrm{M} \pm \mathrm{m}) \\
\mathrm{C}, \% \\
\mathrm{P}, \% \\
\text { Лимиты }\end{array}$ & $\begin{array}{c}9,3 \pm 0,4 \\
9,3 \\
2,4 \\
6,2-11,0\end{array}$ & $\begin{array}{c}9,0 \pm 0,8 \\
13,3 \\
3,1 \\
7,6-11,1\end{array}$ & $\begin{array}{c}9,1 \pm 0,5 \\
7,9 \\
2,2 \\
8,6-9,5\end{array}$ & $\begin{array}{c}9,1 \pm 0,4 \\
8,9 \\
3,0 \\
8,2-9,3\end{array}$ \\
\hline
\end{tabular}




\begin{tabular}{|l|c|c|c|c|}
\hline Ширина чашелистиков, мм & & & & \\
$\mathrm{M} \pm \mathrm{m})$ & $9,2 \pm 0,4$ & $9,2 \pm 0,6$ & $9 \pm 0,7$ & $9,7 \pm 0,5$ \\
$\mathrm{C} \%$ & 11,0 & 14,4 & 6,9 & 9,6 \\
$\mathrm{P} \%$ & 3,6 & 3,3 & 2,1 & 2,9 \\
Лимиты & $6,0-9,6$ & $7,3-10,9$ & $8,2-9,6$ & $9,5-9,8$ \\
\hline
\end{tabular}

Средний размер ягод по местонахождению в окр. с. Зимовье о,53 г, размах на делянках составил от 0,40 г до о,66 г, такой размах по массе ягод говорит о высокой вариабельности данного признака в этой популяции. Вес самых крупных ягод равен 2 г. Урожайность от 70 до 123 г/ $\mathrm{M}^{2}$.

Растения Fragaria viridis (клубники) на юго-восточном склоне г. Сокольная на территории Алтайского ботанического сада и выше по склону, произрастают небольшими, редкими куртинами от о,8 до 1,5 $\mathrm{M}^{2}$. Общее проективное покрытие составляет $2 \%$. Освоение этих площадок клубникой происходит интенсивно, средняя плотность особей на 1 кв. м. составляет 144 шт. (42 шт. растений генеративных и 102 шт. вегетативных). В процентном соотношении доля генеративных особей составляет 21,9 \%, ювенильных 78,1\%. Раньше на этих площадках отмечалось значительно меньшее количество вегетативных растений. По характеру возрастных спектров Fragaria viridis - земляника зеленая относится к ЦП инвазионного типа с доминированием молодых особей, кривые возрастного состава левосторонние. Отражают инвазию (заселение) вида на свободные экониши и к ЦП нормального типа, кривые возрастного состава которых близки к кривым нормального распределения.

Высота цветоносов изменяется от 9,9 до 17,2 cм, количество цветков и ягод на одном цветоносе 4-6 шт., а количество цветоносов на растении составляет 1-2 шт. 36 г/ $\mathrm{M}^{2}$.

Средний размер ягод 0,49 г, вес самых крупных ягод равен 0,9 г. Урожайность 18-

Ценопопуляция Fragaria viridis в урочище Чашино произрастает небольшими, редкими куртинами от 1,0 до $2,5 \mathrm{M}^{2}$, на площади 68 га. Средняя плотность особей на 1 кв. м. составляет 154 шт. (47 шт. растений генеративных и 107 шт. вегетативных). В процентном соотношении доля генеративных особей составляет 30,5\%, ювенильных 69,5\%. Высота цветоносов составляет от 7,6 до 9,9 cм, в среднем 8,8 cм, количество цветков и ягод на одном цветоносе 2-7 шт. Средний размер ягод 0,51 2, вес самых крупных ягод равен 1,3 г. Урожайность $30-58$ г / ${ }^{2}$.

Популяция Fragaria viridis вокруг Быструшинского водохранилища, представлена растениями в северо-восточной части Первого претора, на площади 31 га и на открытой насыпи (дамбе) - 6 га. Общее проективное покрытие земляники составляет 5-7\%. На $1 \mathrm{M}^{2}$ насчитывается от 85 до 120 растений, которые угнетены из-за плохо развитого почвенного слоя, полученного путем насыпи из крупного щебня при возведении плотины 42 года назад. Механические свойства субстрата не способствуют заглублению корневища, в результате чего оно вместе с почками возобновления располагается на поверхности почвы. На корневище одновременно развивается большое количество побегов возобновления (рамет). Именно мощные корневища, формирование которых стимулировано одновременным развитием большого количества побегов возобновления, обеспечивают выживаемость вида.

Высота цветоносов от 9,5 до 10,6 cм, количество цветков и ягод на одном цветоносе 4,4-5,6 шт. Средний размер ягод 0,41 2, вес самых крупных - 0,8 2. Урожайность 23 г/м ${ }^{2}$.

Из трех местонахождений и восьми экологически отличных друг от друга мест, вегетативным путем в количестве 15-20 шт. (с каждого места) перенесены растения Fragaria viridis на интродукционный участок (таблица 3). 


\section{Морфологические характеристики растений Fragaria viridis интродуцированных из природных местообитаний в Алтайский ботанический сад}

\begin{tabular}{|c|c|c|c|}
\hline Местонахождение & Номер делянки & Высота растения, см & Длина корневища, см \\
\hline \multirow{5}{*}{ Окр.с. Зимовье } & 1 & $17-22$ & 6-9 \\
\hline & 2 & $12-15$ & $4-7$ \\
\hline & 3 & $8-10$ & $4-6$ \\
\hline & 4 & $18-23$ & $6-9$ \\
\hline & 5 & $17-21$ & 9-15 \\
\hline \multirow{2}{*}{$\begin{array}{l}\text { Быструшинское } \\
\text { водохранилище } \\
\text { (насыпь) }\end{array}$} & 1 & $14-17$ & $11-21$ \\
\hline & 2 & $4-8$ & $3-5$ \\
\hline $\begin{array}{lr}\text { Подножие } & \text { xр. } \\
\text { Ивановский } & \text { база } \\
\text { отдыха } & \\
\text { «Вертикаль» } & \end{array}$ & 1 & $10-12$ & $4-6$ \\
\hline
\end{tabular}

Данные таблицы показывают, что в каждом местообитании есть одинаковые экологические ниши. Например, хорошо развитая растительность, высотой не более $40 \mathrm{~cm}$, мощный почвенный слой, хорошее увлажнение создают условия для отличного роста и развития растений. У этих растений высота составляет 17-23 cM, длина корня 6-15 cM (делянки № 1, 4, 5 в окрестностях с. Зимовье), делянка № 1 с Быструшинского водохранилища.

На делянках, где плохо развит почвенный слой, как следствие, бедная растительность, не способствующая сохранению влаги, высота растений 8-10 cм, длина корня 3-6 cм. (делянки № 2, 3 в окрестностях с. Зимовье), делянка № 2 с Быструшинского водохранилища и делянка № 1 подножие хр. Ивановский (база отдыха «Вертикаль»). Числовые данные морфологических признаков показывают существенные различия. Приживаемость растений $100 \%$. Все это показывает экологическую амплитуду и величину экологоморфологической реакции растений.

\section{Результаты}

При изучении Fragaria viridis - земляники зеленой в отличающихся экологических условиях получены данные о варьировании различных параметров: количество особей в исследуемых ценопопуляциях изменяется от 60 шт./ $\mathrm{M}^{2}$ на открытой поляне вдоль p. Ульбинка до 247 шт./м² близ с. Зимовье; проективное покрытие земляники в зависимости от местопроизрастания колебалось от 2-5\% в большинстве местонахождений до 15 \% близ с. Зимовье. Урожайность в исследуемых ценопопуляциях земляники изменяется от 23 г $/ \mathrm{M}^{2}$ до

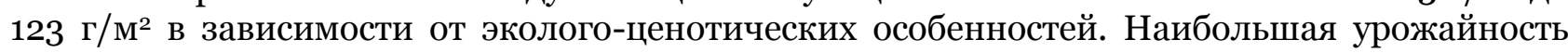
ягод земляники зеленой $\left(123 \Gamma / \mathrm{m}^{2}\right)$ отмечена близ с. Зимовье, минимальная $\left(23 \mathrm{\Gamma} / \mathrm{m}^{2}\right)$ зафиксирована вдоль р. Ульбинка из-за обработок близлежащих полей подсолнечника ядохимикатами и на северо-восточной части Быструшинского водохранилища из-за слабого почвенного горизонта.

Максимальными морфометрическими показателями характеризуются растения в окрестностях с. Зимовье, а минимальными в северо-восточной части Быструшинского водохранилища. Среди изученных морфометрических показателей наиболее вариабельными признаками являются число цветков в кисти, коэффициент вариации от $18,5 \%$ в северо-восточной части Быструшинского водохранилища до 24,5 \% г. Сокольная. Средний и низкий уровень вариабельности характерен для высоты цветоноса от 8,8 \% возле Чашинского водохранилища до 15,5 \% в окрестностях с. Зимовье. Наиболее стабильными признаками являются длина и ширина чашелистиков (коэффициент вариации 2,2-3,6 \%). 


\section{Заключение}

Одним из важных направлений в популяционных исследованиях является изучение механизмов, обеспечивающих устойчивое существование вида в сообществе. Генетическая изменчивость рассматривается в качестве важного фактора, обеспечивающего устойчивость и процветание вида в сообществе. Личные наблюдения и опрос населения позволяют сделать вывод о том, что существование растений клубники разных по возрасту от 1 до 8 лет обеспечивает распространение ее на этих территориях в течение многих (30-40) лет.

По хозяйственным признакам, урожайности с $1 \mathrm{~m}^{2}$, массе 100 ягод выделена популяция близ с. Зимовье. Хорошие фитоценотические показатели (по плотности кустов, их количеству, а также распространению) принадлежат этой же популяции.

Следует отметить, что, несмотря на значительную пространственную разобщенность этих местонахождений по соотношению генеративных и вегетативных особей ЦП относятся к инвазионному и нормальному типам. Это можно объяснить, прежде всего, сходством их эколого-фитоценотических условий, а также существованием данного вида на этих территориях много лет. Данные по возрастной структуре ценопопуляций земляники зеленой позволяют сделать вывод о способности популяционных систем к самоподдержанию и их устойчивости.

\section{Примечания:}

1. Вигоров Л.И. Сад лечебных культур. Свердловск, 1976. С. 76.

2. Атлас дикорастущих растений Ленинградской области. М.: Товарищество научных изданий, 2010. С. 324-327.

3. Лавренова Г.В., Лавренов В.К. Энциклопедия лекарственных растений. Донецк: изд. Донеччина, 1997. С. 324-327.

4. Киселева К.В., Майоров С.Р., Новиков В.С. Под ред. проф. В. С. Новикова. Флора средней полосы России: Атлас-определитель. М. изд. ЗАО «Фитон +», 2010. С. 292.

5. Флора Казахстана. Алма-Ата: изд. АН Каз. ССР, 1961. Т. 4. С. 415-417.

6. Раменский Л.Г. Учет и описание растительности на основе проективного метода. М.,: Изд-во Всесоюзной Академии с.-х. наук им. В.И. Ленина, 1937. 69 с.

7. Скрябина А.А. Методика исследований. К методике изучения запасов плодов дикорастущих ягодников.// Растительные ресурсы. 1978. T. XIV. Выпуск 4. С. 599-601.

8. Ирошников А.И., Мамаев С.А., Правдин Л.Ф., Щербаков М.А. Методика изучения внутривидовой изменчивости древесных пород // Центральный НИИ Лесной генетики и селекции. М.: 1973. 31 с.

\section{References:}

1. Vigorov L.I. Garden of medicinal plants. Sverdlovsk, 1976. p. 76.

2. Atlas of wild plants of the Leningrad region. Moscow: Association scientific publications, 2010. pp. 324-327.

3. Lavrenova G.V., Lavrenov V.K. Encyclopedia of Medicinal Plants. Donetsk: Donechchina, 1997. pp. 324-327.

4. Kiselev K.V., Mayorov S.R., Novikov V.S. Ed. prof. V.S. Novikov. Flora of Central Russia: Atlas-determinant. Moscow: ed. CJSC "Fitton +", 2010. Pp. 292.

5. Flora of Kazakhstan. Alma-Ata: ed. SA of Kaz. SSR 1961. V. 4. pp. 415-417.

6. Ramenskiy L.G. Accounting and description of the vegetation on the basis of projection method. Moscow, Univ-Union Academy of Agricultural Science them. V.I. Lenin, 1937. 69 p.

7. Scriabina A. Research methods. To the methods of studying stocks fruits wild berries // Plant Resources. 1978. V. XIV. Issue 4. pp. 599-601.

8. Iroshnikov A.I., Mamaev S.A., Pravdin L.F., Shcherbakov M.A. Method of study of intraspecific variation of tree species // Central Research Institute of forest genetics and selection. M., $1973.31 \mathrm{p}$. 
УДК 58.009

\title{
Изучение основных фитоценотических и хозяйственных признаков земляники зеленой Fragaria viridis (Duch.) Weston. в природных условиях (Восточно- Казахстанская область)
}

\author{
${ }^{1}$ Татьяна Афанасьевна Вдовина \\ ${ }^{2}$ Ольга Анатольевна Серова \\ 3 Нина Миратовна Каданцева
}

1-3 РГП на ПХВ «Алтайский ботанический сад» КН МОН РК, Республика Казахатан

Кандидат биологических наук, ведущий научный сотрудник

E-mail: altai_bs@mail.ru

2 Старший агроном

E-mail: altai_bs@mail.ru

3 Младший научный сотрудник

E-mail: Nina_badreyeva@mail.ru

Аннотация. В статье приводятся данные фитоценотических и хозяйственноморфологических признаков Fragaria viridis Duch. - земляники зеленой в различных местонахождениях. Наиболее устойчивое существование вида в сообществе отмечено близ с. Зимовье. Соотношение генеративных и вегетативных особей в изученных ценопопуляциях позволяет отнести их к инвазионному и нормальному типам.

Ключевые слова: Fragaria viridis Duch.; местонахождение; ценопопуляция; изменчивость; признак. 